\title{
Learning Body Techniques: Dance and Body Flexibility among Gay Black Teens in Salvador de Bahia, Brazil
}

\author{
Maycon Lopes (D)
}

check for updates

Citation: Lopes, Maycon. 2021. Learning Body Techniques: Dance and Body Flexibility among Gay Black Teens in Salvador de Bahia, Brazil. Social Sciences 10: 72. https://doi.org/10.3390/socsci1002 0072

Academic Editors: Thomas Johansson and Jesper Andreasson

Received: 1 November 2020

Accepted: 8 February 2021

Published: 15 February 2021

Publisher's Note: MDPI stays neutral with regard to jurisdictional claims in published maps and institutional affiliations.

Copyright: (C) 2021 by the author. Licensee MDPI, Basel, Switzerland. This article is an open access article distributed under the terms and conditions of the Creative Commons Attribution (CC BY) license (https:/ / creativecommons.org/licenses/by/ $4.0 /)$.
School of Philosophy and Human Sciences, Federal University of Bahia, Estrada de São Lázaro, 197-Federação, Salvador 40210-730, Brazil; mayconslopes@gmail.com

\begin{abstract}
This article is the result of ethnographic fieldwork among amateur dancers, mainly among gay adolescents from the outskirts of Salvador de Bahia (Brazil), who label themselves as "flexible". This self-definition arises out of bodily flexibility techniques, cultivated through intense physical work. By focusing on specific training situations, such as stretching exercises, I trace understand how the "flexible" body is built. I propose that the language mobilized by these young people offer an important guide to understanding the distinctive elements of this practice. The practitioners' accounts and my own observations of the practice indicate that the embodiment of acrobatic skills occurs in a process that weaves body and environment. Following Ingold, I argue that an ecological approach help us to comprehend this kinesthetic practice as spatial realization, as well as providing useful insights into its learning practices exploring the richly sensory dimension of learning practices and development of motor sensibilities, such as the sound and the imperative pain experience. Furthermore, I analyze how my interlocutors' concept of body fits the theoretical idea of how bodies should not be defined by what they are, but rather by what they are able to do.
\end{abstract}

Keywords: embodiment; apprenticeship; LGBTQ youth; dance; leisure; gymnastics skill; movement; injury; space

\section{Introduction}

After almost a decade of experience with dance culture among gay teenagers of color who live on the outskirts of the city of Salvador de Bahia, I have heard and observed many stories that testify to the personal, physical, and real involvement of many of them with dance. Participation in dance groups made up of gay friends and neighbors that rehearse and present choreographies to popular dance music, is part of the trajectory of their construction of a sense of gay self and identity.

My ethnographic subjects, the majority of whom are participants or ex-members of such dance groups, are part of that section of the gay community for whom this artistic activity seems to offer an environment of playful sociability sufficiently open to an exploratory attitude in terms of a kinesthetics that is non-normative in relation to gender.

For the purposes of this article, I only consider amateur gay dancers who, referring to a set of bodily flexibility techniques which they learn, call themselves flexible. Many of the movements that they perform, such as jumps with the legs far apart, acrobatic maneuvers and gestures that position the torso out of vertical axis, are characteristic of rhythmic gymnastics and contortionism-gymnastic modalities that require extreme flexibility. These gymnastic movements present an affinity, for example, with the pelvic and sexualized movements performed in choreographies of some of these dance genres. The combination of this kinesthetic repertoire with popular music rhythms has become a tradition among gays on the urban peripheries throughout Brazil. Such a practice, however, is still scarcely researched.

While I translated the emic category with which my interlocutors designate themselves, "flexible gay", as "flexible gay man", with the intention of producing a more fluid 
text for the Anglo-Saxon reader, I need to underline something that may be concealed by this translation. It is interesting to note the torsion commonly operated by the word gay, a sexual identity whose use in Brazil, does not require the noun (such as "man"). The flexible gay youths who participated in the research refer to their colleagues not only as gay, but nearly always, as "the gay (a gay)"-understanding that the " $a$ " is the feminine definite article in Portuguese.

If at times they reserved this linguistic construction for people with whom they were not particularly sympathetic, they generally interact with their friends referring to them as viado or bicha. These are the names that, like queer, are "used both pejoratively and as a term of self-affirmation for people of nonconforming gender and sexual identities. Its closest equivalent in American English would be somewhere between 'queen' and 'faggot'" (Pereira 2019, p. 63).

The aim of this paper is to explore the training through which one creates a flexible body. As I will show, the pathways to how these flexible gay men learn, highlight a relationship between themselves and their environment. The development and improvement of kinesthetic abilities is therefore considered to be a primordial intersection between body and place-a surrounding space that should be understood as a world made up of diverse objects and components.

Even if the findings of the study provide elements for a dialogue with authors whose ideas are useful for the discussion that I undertake regarding the body and learning processes, such as John Dewey (2004), Marcel Mauss (2007) and Bruno Latour (2004), a large part of the analysis that follows is informed by the anthropology of Tim Ingold. His theoretical elaborations are based on the understanding that we are immersed in a world that is not neutral or merely a receptacle of actions, but is an environment that is itself, with its materials, active, and with which we are actively engaged.

I argue that becoming a flexible gay man is also, therefore, a question of spatial involvement. In attempting to understand how the formation of this body takes place, the connection with the environment is also revealed through sound. The sounds that result from the impact of a body that is acrobatically launched onto a specific surface can also be heard when we pay attention to the retelling of their performance of the flexible gay men themselves. The onomatopoeia participates in the narratives produced, investing them with more reality, to the extent that the sound calls our attention to the richly sensory facet of the practice; on one hand, for the effects, including the noises, provoked by the sudden character of some movements, and on the other, regarding how the movement is experienced.

The topics considered here regarding the theme of the assimilation of these gymnastic abilities emerge, therefore, not only through the descriptions produced through participant observation, but from the retelling of the flexible gay men. In this direction, the language of my research participants employs expressions that are key to understanding the practice and of the physical transformation that makes them competent to act in the "dance world" as flexible gay man.

This article does not intend to exhaustively describe the routes of assimilation of the abilities of the flexible gay man. Exploring some of them, however, already implies in us considering a relationship with pain, understood as a crucial dimension of the stretching exercises. Stretching and being stretched is preparing the body for the art of flexibility. It is a realization that puts them into relation through touch and instructions, the coupling with objects, the production of noises and the sensation of pain. This is the environmental, practical, and sensory network with which the pain works together, as a significant aspect of the formation of a flexible body.

The following section of the manuscript aims to familiarize the reader, with the available literature, regarding the wider cultural context in which the practice of flexibility is situated. Following this, I outline some methodological considerations regarding this research and, before proceeding with the analysis itself, I show an ethnographic vignette in which a flexible gay is in action. 


\section{Background}

Although the relationship of LGBTQ people with dance has only been the explicit object of attention in the social sciences a few times, in sexuality studies developed in Brazil, mentions to dance, generally of a recreational nature, are frequent. Be it in an indirect manner or as emerging more directly from a research question, we are able to find reports regarding the role of homosexuals from the Brazilian urban periphery in public dance presentations in diverse research settings that range from the popular street party (Noleto 2016; Bilate 2017; Silva 2019) to the religious field, notably Afro-Brazilian religions ${ }^{1}$ (Landes 1940; Leacock and Leacock 1972; Fry 1986; Birman 1995).

Keeping in mind the differences between contexts and the dances enacted, dance emerges in related studies, as suggested either by the researchers or by the interlocutors, as a locus of gender and sexuality production, in these spaces that open materially to the artistic agency of these gay youths. Taking as our premise the capacity of bodily movements, in which all dance consists, to socially position its practitioners in terms of sexuality and gender, is particularly important here.

Firstly, because the techniques of bodily flexibility of the participants of this research are incorporated in the performance of dance genres whose choreographies already reserve for the dancers a markedly gender binary. The favorite dance genres of the flexible gay men, which are also some of the most popular among the poor, black urban youth of the city of Salvador de Bahia, are funk carioca and pagode baiano.

Funk carioca is an electronic rhythm influenced by Miami bass, a variety of US hip-hop (Palombini 2013) and by freestyle, while pagode baiano has its origins in a rereading of the so-called samba de roda, a music produced using a combination of hand percussion and drums, accompanied at times also by a type of guitar (cf. Cambria 2014). Despite having distinctive formative backgrounds, there are some points in common in the experience of enjoyment and consumption of these rhythms that should be highlighted. Both funk carioca and pagode baiano tend to be danced in groups, generally made up of people of the same gender.

Many lyrics, from both genres, have a sexually suggestive tone, when not openly so. Their energetic and pulsating rhythms, played at loud volume, are habitually choreographed according to the gender of the dancers. In their ethnography into funk dance parties, for example Mizrahi (2019) observed that in their dancing, the women, while bending their knees, simultaneously placing their hands on them, bent their torso forward and threw their hips back. At times which squatting down, they raised and lowered their buttocks. The men made an inverse movement, launching their hips not backward, but forwards, with a focus on the genital area.

It is possible to imagine, based on the descriptions of Mizhrari the simulation of sexual acts through the dance. In a similar sense, another funk ethnographer mentions the "pumping and thrusting gestures" (Sneed 2008, p. 74), set in an atmosphere of intensity, power, abundance, energy, and vigor. It is certain that the funk and pagode choreographies are "technically demanding moves that require a lot of strength and skill" (Toth 2017, p. 292), and often infused with a "violent and sexual aesthetic" (ibid., p. 300).

Such characteristics, attributed by Lucille Toth to twerk, a style of dance originally popular among Afro-American women and LGBTQ youth of color, and which is also characterized by "a sexually provocative manner [to dance], involving thrusting hip movements and a low" (Toth 2017, p. 292), could be extended to pagode and to funk.

Flexible gay men produce a bricolage based on the creative incorporation of gestures conventionally codified in terms of gender and diverse elements of rhythmic gymnastics, which has also been referred to as the most female of sports (see Hökelmann et al. 2013) to the repertory described. This admixture stylized the performance, emphasizing, through some movements, such as leg extensions, the sensuality and femininity of that body. There

1 It is worth noting that possession phenomena, through which deities are worshiped in these religions, presenting themselves in public ceremonies, are marked by dance. The dance for the saints is also a way of revering them in such rites. 
is another relationship between the dance and the production of gender which is important to highlight.

As I observed in this ethnographic immersion, the kinesthetic practices of the flexible gay men are associated with a typical way of being gay in the outskirts of Salvador, and maybe in many Brazilian suburbs. The deliberate investment on the part of these subjects in femininity, however, is very common, which translates via certain bodily attitudes (including the way of talking) or via the use of some props and outfits. Many flexible gay men, for example, tend to have short shorts, an outfit generally associated with the 'feminine'.

I am not the first author to observe this particularity, even given that showing oneself to be feminine in this context, far from being a lesser or subtle question, seems more like a first order question that appears most important and is easily visible. In this manner, the Australian anthropologist Jim Wafer, in fieldwork in the 1990s in Bahia, identified the use of the word fechação, considered to be "a kind of extreme form of estrelismo ('star-ism')" (Wafer 1991, p. 35), to characterize the extravagance, common mainly among Brazilian transgender women. The fact that this behavior warrants a special term attests to the unequivocal way its typicity.

Although he does not use the vocabulary, performance equivalent to fechação can be found in the descriptions of Birman (1995) regarding the role of homosexuals through dance in an Afro-Brazilian religion. The anthropologist colors her ethnography with expressions such as exhibitionism, excess, exacerbation, exaggeration. As she demonstrates, the attribute of 'excess' to qualify the performance of homosexuals is connected with transgression that operates on new gender norms. They are not only exaggerated gestures but exaggeratedly feminine gestures.

With all this in mind, if funk carioca and pagode baiano tend to be danced in groups divided along gender lines, it is easy to suppose that it is not on the men's side that the flexible gay men wish to dance. The flexible gay men mark their inclusion in the category "man" by dramatizing their femininity through certain bodily movements, but also in the way in which they interact with one another, as I will explain.

Gender as a kinesthetic production will be the topic of future papers. In the meantime, I believe that the persistence of the reports of the affinity between gay men and dance invites us toward a consideration of bodily life in sexuality studies. This article is specifically concerned with the preparation of this body that seeks to draw attention to itself through hard, fast and aggressive movements. By placing the analysis at the level of preparation, it highlights an ecological weave that the flexible body mobilizes and in which it crucially finds itself involved.

Although this study is not based on learning theories, a plurality of perspectives in this direction have been adopted in fields such as sociology, psychology, pedagogy and much else besides. These heterogeneous perspectives, made up of a growing body of literature (see Larsson 2020), provide theoretical insights and offer responses for researchers interested in exploring the acquisition of physical skills.

It is certain that we could, in light of the set of concepts that these analytical frameworks employ, engage in a dialogue with these theories. In some sense, the lines of thinking in this article do this implicitly. This is because these approaches are necessarily based on certain conceptualizations, imploding or reinforcing dichotomies, such as mind/body, representation/practice, body/environment, putting notions such as learning, body, and skill to work and incorporating and privileging certain elements, such as landscape, so as to make the process of developing physical skills intelligible.

Therefore, at the end of the day, the reader familiar with different learning theories, even if a detailed exploration is absent from this text, will potentially encounter connections and incompatibilities between the way that I seek to take the physical training which creates a flexible body into account and the assumptions which underlay learning theories, their research agendas, the debate regarding paradigms that they provoke and the advances 
in understanding that they employ in many of their analyses. We share, finally, certain concerns, such as an examination of the education movement.

\section{Research Context and Methodological Considerations}

The term fechação explorated by Jim Wafer (1991) did not disappear in the 1990s. This term was frequently used by my interlocutors, around 30 years after the anthropologist carried out his ethnography in Bahia. Associating the term with performance in the field of flexibility signified appreciating the excellence of a dancer and their skill.

The act of calling attention to oneself, a behavior that even heterosexuals from these suburban areas expect their gay neighbors to demonstrate, clearly connects itself with the practice of flexibility, and with a competence in certain bodily techniques. The art of flexibility updates the disruptive gesture of calling attention to oneself, proposing a specific and demanding kinesthetic grammar. As will be seen, it will be hard to perform acrobatic body techniques if one does not persevere, day after day, in the practice of flexibility.

Before becoming flexible, all the gays in this research learned how to dance. Many of the youths with whom I worked were, during the field work, linked with or (were ex-members of) dance groups, formed in general by people from their neighborhood-gay men and women. These groups were the way in which many of them were introduced to the "dance world" and to the art of flexibility.

My introduction into the practice also took place through one of these groups. Interested in getting to know these youths who showed themselves capable of extraordinary bodily movements, I approached a dance group from the suburbia in Salvador de Bahia, with the initial intention of following their rehearsals. I began to visit the house of one of the members, where they got together to rehearse as well as to hang out. Run by a warm and inviting lady, the mother of one of the group members, her house was a meeting place for these youths.

I speak of "some" of these youths, because it did not take long for me to get to know the rest of the group through accompanying them not only in their rehearsals, but also in their shows in the neighborhood theater. In these outings, I naturally got to know other flexible gay men, who took me to other houses, neighborhoods, and spaces in the city where flexibility was center stage.

During the participant observation that I conducted, which lasted approximately eight months, I got to know and live with 50 Afro-Brazilian youths. Among these, a fairly small number were female practitioners of flexibility, gays friendly to the practice and many flexible gay men, whose age varied between 13 and 21 years of age, with the great majority being around fifteen years old.

It took me a while during my research to understand that "why", the reason that led a gay to want to be flexible, was not a useful question to ask them. The most I got were evasive and disinterested answers; aspirants to flexibility do not usually waste time on these questions. Their most pressing concern revolves around the "how". While social scientists are debating about the meanings attributed to a given reality, those aspiring to flexibility are more interested in a practical question, to which "representations" would be insensible. Thus, it is not useful for solving their problems.

I understood, therefore that participant observation would be not only, personally the most stimulating way to study the practice of flexibility, but also the most sensitive manner, participating effectively in the day-to-day workings of the meetings of flexible gay dancers and observating how their learning happens. Although the house that I mentioned above, and that was part of my routine for months, was one of the main scenes for stretching that I present in this study, the context for learning in general was more diffuse, immanent to the practice and to the encounters that it tended to generate. In this manner, it was not only in that house that I learned how the newcomers are initiated and how experienced practitioners were looking to "evolve", a verb that synthesizes both the pursuit of excellence in bodily flexibility techniques, as well as the acquisition of new postures in their repertory of gymnastic skills. 
In the fieldnotes that I carried in my backpack, I recorded my field observations. In contexts such as parties, where it would appear ridiculous to be seen taking notes, I opted for recorded voice memos. It did not matter how quickly I was able to make the notes however, they were still unable to capture the velocity of the movements of the bodies of the flexible gay men.

I started then to add some drawings to these notes, which even if rudimentary-because I was drawing in the heat of the moment-could serve as a support for my memory, whereby, on returning home, I attempted to recover the details of the immersive experience and flesh out the notes in greater detail. Even so, despite the pictorial resources and support of my short-term memory, the task of describing those complex movements remained arduous-a challenge that may have something to do with my limited ability as a dancer. Therefore, I added video recording to my research data. I used it only as an aid for the writing, as a tool which met a descriptive need.

The videos that, through allowing the circulation of the practice on social networks and social media, were meaningful for flexible gay men learning the practice, also became active ingredients in this research. The videos and their production acted to set the scene. Often, the flexible gay men left their phones with me, asking me to record their performance using phone cameras. It was a way that I found to be useful in some manner in the field. Sometimes these videos were circulated on the Internet, and they were frequently used so that the flexible gay men could evaluate their own performance. Both video and photography acted in this study. Still and moving images were used including to document the materiality of the place, since this article seeks to address the learning from its environmental aspect.

Throughout the course of this research, I digitally stored a range of multi-media from the field. My smartphone was full of these videos, since I was also in the Whatsapp group of the flexible gay men, where videos were shared daily. Participating in different meetings and contexts, the use of multimedia data reflected, therefore, the multimodality of the field itself (Dicks et al. 2006), where on numerous occasions, I had cause to interact with these data.

Given that every medium presents itself in different ways and according to specific affordances (ibidem), the videos are especially promising and useful for the research into movement cultures, since, putting images into slow motion, we can alter the speed of the moving bodies, as well as put the scene into rewind (switching backwards and forwards).

The process of transcribing the audio records, produced during the fieldwork, as well as the descriptions at times supported by the visual pieces (initially organized chronologically), allowed me to immerse myself once again in the research context, recreating the feeling of "being there". The fieldnotes worked in tandem with these various types of qualitative data, and collaborated to situate the specific topics, through details from the observant participation, in their context. The analysis of this data consisted of identifying manually the recurring themes that appeared in the descriptions. The written material was organized based on these key themes, more than in a sequential or temporal manner.

I could not restrict the data analysis to being a "step" in the research process; more precisely, data analysis procedures must be considered to be an "instance" intrinsic to the wider research process. This process does not begin once data collection is complete (Aull Davies 1999). Firstly, because the description does not generate "brute data". As Ingold argues (Ingold 2011, p. 237), "any act of description entails a movement of interpretation". This movement clearly occurs "from a particular vantage point" (ibidem), which requires an analysis of the ethnographer's position as well, since it will affect the interpretations-something that cannot be realized in this manuscript specifically.

The data analysis effectively participated in the data production, on one hand, because I carried out the descriptions during the research, on the other because I generated codes and detected main themes based on the data throughout my time in the field. This ongoing mapping process allowed: (a) for emerging categories in the analytical process, so as to refine my attention regarding aspects of the experience of dancing during participant 
observation; (b) to reassess research questions and embrace new ones; (c) to deepen other pertinent topics in conversation with the research participants, and include these topics in eventual and subsequent interviews; (d) to confirm some interpretations and enrich my understanding of certain indigenous terms, including those related to bodily movements.

As coding proceeded, I also highlighted significant ethnographic vignettes and the most illustrative and strongly imagistic of the participant's accounts, consistent with the research questions. During data analysis, I defined bodily movements, training exercises, bodily sensations and the specific vocabulary dancers used to talk about flexibility. Instead of adopting a rigid and imperative conceptual framework, the knowledge produced here emerged through the particularities of the categories identified and their relationship to the existing literature.

Considering the mobile visual data, the section that follows is part of the exercise of, through slow motion viewing as a key process in the analysis (Collier and Collier 1986), bringing the movement into the written text, trying to capture the dynamism of the dancing body.

\section{The Scene}

The scene ${ }^{2}$ is of a large garden or park. In front of a wall, Jonathan, an adolescent wearing a baggy T-shirt and short shorts, after dancing energetically with his buttocks, rhythmically moving them backwards and forwards, proceeds into a daring maneuver. More or less two and a half meters separate the top of the wall, from the ground on the other side, the wall is not so much of an obstacle as a launch pad or an opportunity. Intrepid, scaling the wall impetuously, it is from here that Jonathan gathers force and jumps, doing a split jump and launching himself forward. While still high in the air, he stretches his legs wide, which will, however, only achieve full extension when perpendicular to the ground, with which his body brusquely collides. He falls into the full split. Due to the force of the friction, and the impact of the fall, we can now see his legs stretched out at an angle of 180 degrees over the surface of the ground-in the grassy area where the party that Jonathan is participating in is taking place.

His friends cry out a ringing "viaaaado". Tumult ensues. The reactions that mix together with the background music, are of perplexity and enjoyment. Jonathan, who remains on the ground, but still with energy and showing no pain from the jump, continues in the strident intensity of his movements.

Keeping his legs extended over the grass, the choreography that he performs, with the help of the palms of his hands resting on the ground, consists of raising and hitting his pelvis rhythmically and suggestively on the ground. Jonathan shows that for the able dancer in motion, there is no time to show pain. Between the pirouettes with which he entertains his spectators, our dancer stand up. He lifts up his right leg while maintaining his left leg planted firmly to stabilize himself, pulling his leg up by the ankle with the help of his right hand, and thereby bringing it up to his head.

Both hands meet and grip his right ankle. His right foot is now extended up to his head, while the left foot continues to act as a support. A straight line is formed by the near continuous verticality that follows from one leg to the other. The phrase from head to toe no longer applies, but rather from one foot to the other. This platform (standing split) is created by the mischievous dancer, maybe just long enough to remove any doubt that he has control over the position. In addition, when a lack of balance appears to threaten to overcome the performer's balance, the impression is interrupted by another acrobatic trick.

The trembling of this platform erected by Jonathan is succeeded by the violent movement of his right leg, high up, which drives the flinging of his whole body to the ground. His body trembles, tilts and falls to the ground. As if being pushed, Jonathan's trunk and head heed gravity's call: kissing the right leg of the body as it falls. And on it goes.

2 Curiously, this iconic scene already circulated on a page of humor that had 3 million followers on Instagram. 


\section{Having a Body}

It is not only in the literature on habits and skills, which I will consider in the following that they are alluded to in terms of acquisition. Flexible gay men understand that defining themselves as "flexible"-as will become clear, assumes as its framework having rather than being-wherein it is necessary to acquire skills for a set of movements and postures. It is a common way of speaking for them to use the verb to have, to refer to what the body can do. Charles, a flexible gay man, tends to say for example: "I have a spine". Taken out of the practical context of flexibility, his statement appears redundant or would be oddly received. As he makes a point of clarifying throughout his argument:

"The sis that can't handle it posts a pic of someone else and calls it a spine. Hey, girl ... You call that a spine? Yeah"-he states, flatly. And he continues: "Sure, everyone has one [spine], right? But well, not everyone has as flexible a spine as I do, as Richard does, as Nikolas does, and as many other people have, but not you, sister, not you".

The clarification concerning these acquisitions, however, exceptional in the field. The claim "I have a spine", or "Charles has a spine" (to refer to someone else), rarely comes with further explanation-being dispensable in the context of flexibility. In the practice of bodily flexibility, having a spine means that the dancer is able, in a front split, to bend the spine backwards and forwards, bending back the torso so as to bring the top of the head as close to the area behind the knee as possible-or "to glue the spine on the front split", as the flexible gay men would say. The extent of this contortion will define the quality of your spine. More than that, the appreciation of the extent of the contortion reveals the existence or not of a spine, it establishes who has and who does not have a one.

The commensurability that is produced between bodies through this parameter and the contortionist ability can at times serve fairly practical ends, for example, for competition purposes, and even to create an ethics related to rivalry-topics that I will not be able to explore further in this work. Competition, however, is not exactly the focus of the parties or diverse contexts in which the dancers show off their prowess in the art of flexibility. The confrontation between performers, when not explicitly aimed at, is a possibility almost always taken into consideration. There is, therefore, an incipient ethics, always ready to put into opposition gay men whose bodies have equivalent skills or similar levels of "career" and performance. Competition is one of many situations in which the enunciation of skills, "to have a spine", can become relevant.

Well, as we are talking about the world of flexibility, we should keep in mind that skill is always the ability to perform a specific activity. It would be useful to think of the concept of ability according to what Nash (1999) points out about the notion of habitus in Husserl's thought. For the phenomenologist, the habitus is "constituted in lived experience and retained by the organism" (Nash 1999, p. 183). This character of possession, so well expressed by "having a spine", is "what makes action possible" (ibid.). In the case of the art of flexibility, these cumulative incorporations make flexible gay men able to be part of the "dance world". Therefore, saying someone does not have a spine means that they do not stand out in a display of flexibility. The body is not divisible, and the spine is, necessarily, part of the dance. However, the spine only steals the scene when it becomes extraordinarily flexible. If this does not happen, then we cannot consider that the skill has been acquired, we cannot consider it as in fact existing.

In John Dewey (2004) acquiring appears as something secondary to the act of inquiring. The latter has an experimental, tentative, exploratory, uncertain character. Yet, acquisition, which may be replaced by the word learning without loss of meaning, happens when the relationship between an activity and its result is finally established. Acquiring would thus involve creating a connection in which through active experimentation, I discover what it is for and how I can manage certain issues. This tool/work combination constitutes the instrumental character itself, strictly linked to the action, which involves [ms1] "having". Attributing the character of a tool to something is, it is worth remembering, to place it into 
relation with a field of practices and, as we will see, with other things that it interacts with (Ingold 2011).

"To have a spine" would be more than knowing how to use it to perform specific movements and poses founded on practical knowledge, it would also be to know that one can rely on it and, therefore, truly own it. If in Dewey (2004) acquisition is a connection, so too is it among flexible gay men. On the one hand, "having" is an achievement that starts from an activity, an uncertain experiment, that may fail. On the other, "having", this achievement that brings a new organ into existence, is a new bodily structure or an instrument, and it is a bond that demands care; after all, we can lose what we have.

In the following lines, I will discuss some ways in which we can make, or equip, progressively and cumulatively, a body aspiring to achieve flexibility.

\section{Another Body}

As we have seen above, there is no neutral body or one that preexists the practice, the process of making it. This is not an exception; even the activities known as innate have their meaning - considered by the pragmatist philosopher John Dewey (2004) as the perception of a reciprocal action between what we do to things and what they do to us-learned, acquired.

It is important to return to the classic essay on the "techniques of the body" by Marcel Mauss (2007), which seeks to consider acquired skills. The Maussian description of the body focuses on what the body can do, on its style and how it is performed, and on the learning dynamics that provide it with know-how by placing the acquired skills in the spotlight, rather than representations or symbolic meanings associated with the body ( Asad 2002).

What makes it possible for Mauss (2007) to attribute the quality of an instrument (of which one could make use) to the body is the possibility, through learning processes, of establishing a connection between making it and specific consequences, which Dewey (2004) also talked about. Or, in the words of the philosopher, the understanding of what things are for and "what can be done and what cannot be done with them" (Dewey 2004, p. 293).

The "effectiveness", which confers this instrumental nature on the body, i.e. that it seeks to produce an effect, both expected and perceptible, is one of the distinguishing features of Mauss' concept of "bodily technique". In addition, I would add: a translation of the link between an action and its result. This original entanglement between body and action, body, and practice, which the reading of the body as the "man's first and most natural instrument" (Mauss 2007, p. 56) suggests, is close to the idea of "having a spine". The way in which the spine comes into existence through practice by which it is produced-flexibility-undoes the apparent univocity to which it is subjected when understood prior to any practice. It is this understanding that makes it possible to judge whether someone has a spine or not. The practices through which a spine can come to be enacted multiply it $^{3}$.

Oral interjections expressing perplexity, enjoyment, and pain, come from the public watching the contortionist performance of flexible gay men. On one occasion, a spectator warned the performer "be careful not to become a paraplegic!", to which he promptly replied: "Have you ever seen an invertebrate become paraplegic?!". This episode demonstrates the difference between the bodies. The way these dancers refer to their bodies forces us to reformulate our fundamentals understandings and parameters to appreciate the constitution of bodies. Bodies cannot be defined if we detach them from the practical configurations within which they act and are created.

The curious thing about this episode is that instead of the key of "to have a spine", the usual condition among flexible gay men, the game of contrasts between a body skilled

3 I am freely inspired here by the treatment offered to illness here by the empiricist philosopher Annemarie Mol (2002). Generally speaking, she argues that if the practices are not placed within brackets, that object which we through to be singular is multiplied, transformed-it begins, in truth, to differ. 
in flexibility techniques and one 'illiterate' in this gestural grammar, takes another path. Invertebrate beings are so named because they have no spine. The formulation that equates flexible gay men to these beings, however, is not at all incompatible with "with a spine". Rather, it highlights the fact that the skills acquired by a body (by which it must be described), changes its shape. Learning therefore, is a movement in which forms are created; a generative process, such that what constitutes a flexible gay man would be a different spine, and not a vertebrate one in the form of the prototype with which we are habituated.

On the other hand, considering flexible gay men to be invertebrates implies that whether undone or reformulated, there is a structure that opposes resistance or obstinacy (perhaps risk) to the practice of flexibility-I refer to the rigidity of the skeleton. If this framework needs to be manipulated to serve the purposes of the art of flexibility, we need to ask ourselves in which laboratory or workshop this happens; better yet: what methods are capable of gestating a flexible gay man's body?

\section{Training}

It is undeniable that competition, sometimes fierce, is part of the practice of flexibility. However, in general, it is in a body-to-body collaboration that a flexible gay man is made. In this sense, the question about "who stretches you" or "who stretched you" is recurrent, referring to a role reserved for another gay, more experienced, who is responsible for training a novice in the art. Learning is an instance of the practice itself, such that learning does not comprise a separate process (Lave 1993). This process is more diffuse and distributed, any flexible gay man able to find another with whom he can exchange knowledge can take part.

The modality of the verb that expresses the act of stretching as a physical exercise, in Portuguese, is commonly reflexive: se alongar. With flexible gay men, stretching is necessary, but the habitual introduction of a mentor, asks the subject to be the patient of the action; to be stretched by someone else. Appearing as the "pacient" in the sentence, however, does not mean that being stretched does away with an active engagement on the part of the novice. There are a variety of configurations in which stretching is conducted.

It can take place by oneself, or in pairs or groups of three or more people. Often, they are called to intervene through touch. For example, two of them may stretch the lower limbs of another, exerting force on the limbs, or giving support so that they can perform a move that they still do not have the skill and balance for. When monitoring a series of exercises, the role of the mentor may include interventions of this nature-which I have called here body-to-body. Stretching someone involves an intervention in the growth of an aspirant to flexibility, or even those who are already flexible, but who are still eager to "evolve".

I occasionally observed flexible gay men stretching under George's guidance. George is 21 , the oldest flexible gay man with whom I spent some time during fieldwork. I do not know whether he stretches at home or not. On the street, however, I only saw him in the role of instructor during stretching training. He is one of the gays with the most prestige in the art of flexibility and propagates an environment that establishes hierarchies among those who practice flexibility: "those who need to stretch are those ones who aren't totally flex yet". He explains in one of our conversations that when you are "flexible", you want to be able to easily hit the ground when you do the splits, i.e., with the speed available to someone who traverses a path supposedly already ready (the expert), "at the shot of a pistol, springing into action at the instant" (Ingold and Vergunst 2008, p. 3). From the perspective of rhythm, we can think of stretching in terms of gradation-and of growth, an idea that I will develop later. Stretching would be a way of making the body grow.

If today he brags about not needing to stretch, George did not reach proficiency in flexibility without suffering and experiencing physical discomfort. When he was in charge of initiating the dance group I followed in this research into the art of flexibility, he said to the group: "They opened my entire leg on the wall. The first time, I pissed myself". 
Disturbed by the outburst, a member of the group asked him: "Why didn't you give up, viado?". George replied: "I wouldn't be who I am today".

\subsection{Among Things}

How the wall comes into this story may not be immediately clear. Firstly, the adventure of searching for bodily openmess ${ }^{4}$, manifested in mobile forms such as the outline of the splits, also presupposes the experience of a particular availability to specific objects (seating such as benches, chairs, and sofas), and to architectural structures (such as walls, streetlights, and curbs). Invited to participate in the practice, these materials are used in different ways in stretching exercises, and the simple display of flexibility. When "opening the legs", i.e., when moving them apart, it is possible to stretch them using a streetlight, when "opened" vertically, or on a curb, when opened more or less horizontally.

Therefore, describing, practicing, or recommending stretching exercises often involves including inanimate entities with which the body learns to enter into a specific relationship of composition. I am in agreement when Bruno Latour (2004) proposes the definition of "body as 'learning to be affected"' (p. 214), since acquiring-a term also used by this author-a flexible body depends on several other elements besides the body itself. As he acknowledges, the advantage of this conception is that the body, by becoming "sensitive to what the world is made of" (p. 206), is addressed to elements with which it articulates and forms itself. We have here legs that are stretched on the wall at home, or perhaps on a streetlight, outside.

On one occasion, a flexible gay man, referring to a handrail of a subway station, said: "I love handrail". On another occasion, when accompanied by another flexible gay men, on encountering one of these handrails, he declared: "I can't control myself, when I see one, I immediately want to do the splits". The handrails is part pf a subway station-like other public spaces, it is favorable to show off your contortionism.

Or, to rephrase, the handrail was not understood merely as an object, but as an active and propositional element, constitutive of an environment in which the practice of flexibility could develop ${ }^{5}$. It demonstrates that the feeling of "loving the handrail" was an active and interested way of engaging with the world. The assumption that this interest is simply projecting onto the handrail the meaning of support for the accomplishment of activity is partial and incomplete, if not mistaken.

In this manner, when we understand that the quality of things is not an element of an autonomous consciousness that gives meaning to a neutral world (Merleau-Ponty 2014), we must take into account that things appeal and suggest behaviors by the quality through which they are revealed (Merleau-Ponty 2008). The style of the vigorous straightness of the handrail seems to serve as an affective impulse, inciting, for example, the movement that arranges the legs as an analogy for the form of the object.

Thus, I understand that the affinity between the style of the thing and the style of the act can promote an affective identification between the practitioner and the thing. I also understand that the subject-or organism, as in Tim Ingold's ecological approach to anthropology (2001)-is a center of perception and agency that grows in the field of relationships. This field of relationships would be the environment itself, with its specific textures and topographies. In Ingold's thinking, environment and organism are relational terms.

My argument, therefore, is that the body is acquired through the actors involving themselves with their environment, which presents itself under certain conditions. It is natural that when moving in the world, the flexible gay man plays and becomes interested in things he finds along the way. After all, things are meaningful, not neutral. Since one

4 This is, to improve the leg extensions.

5 In the study in which they examine skateboarders' skillful mobility in urban environments, Bäckström and Sand (2019) observe that, in the meeting of the skateboarders in these spaces, the environments and objects are imagined as possibly skateable. The authors claim that the imagination of this skateability is anchored in the perception of the materiality of these elements based on their affordances, a way to view the city, "interpreting and imagining the city for spatial and skateable material opportunities" (Bäckström and Sand 2019, p. 9). 
learns to be a flexible gay man by composing arrangements with specific entities, one also learns to notice the opportunities that the properties of these things can offer for flexibility.

An architectural element such as a handrail, however glossy its finish, still seems too rough to awaken any affection or feeling, but a flexible gay men views it differently. More than being an incidental support for passers-by, the handrail's straightness provides an aesthetic prototype for exquisite flexibility. Here, the style suggested by the form, decidedly, invariably straight, is in tune with the beauty "created by the straight lines of the extended human body going outward" (Aalten 2004, p. 267), as the anthropologist Anna Aalten has pointed out about an aesthetic principle of ballet.

Another example of how architectural elements interact with the extension aimed at by certain postures enacted in the practice of flexibility, occurred when, during training sessions, George required that the flexible gay youths, already with their legs extended into a split position, also maintain the extremities of their feet stretched out. "Tips [of the toes]!", George forcefully demanded, while he observed the formation of a parallel between the whole extension of the stretched out legs and feet and the lines drawn by the grouting of the floor of the living room.

\subsection{Toward an Ecological Approach}

In line with what I affirmed, for Ingold (2001), the organism is the link between perception and action. The premise of introducing perception to think the organism is that it is situated in but also constitutes a perceived world. Therefore, without attributing an unequal weight to either of the terms, perception and action coordinate and attune themselves to each other. Through Ingold (2001), we understand that when performing a task, the subject does not detach themselves from the context of corporal involvement; and the greater is his sensitivity to the environment, the greater the possibility of success and adjusting his action to its conditions. The process of acquiring a skill lies in the improvement of this coordination between perception and action.

Ingold (2000) indeed avoids the use of the term "acquiring" to refer to ability. For him, acquiring, linked to the notion of property, would not be an adequate description of learning how to perform a task. Through the organism-environment relationship by which Ingold organizes his thought, he seeks to offer an alternative to certain problems that the term "acquiring" would imply. Thinking about ability as the property of a body can compromise our understanding of the environmental dimension in which tasks emerge and develop.

For Ingold (2000), an ability could more correctly said to be distributed between the components of a field of practice, which is created and allows for the realization of an activity. At the same time, while ability as an acquisition may sound like a fixed property, we lose sight of the fact that the environmental conditions are never the same. When the dynamism and movement of the procedural development of activity can focus on the problem, we reject a solution that resembles the simplicity of the mechanical performance of a task. Because the environments in which sensibilities are generated are not neutral or mere receptacles of actions: they require harmony and care.

Engagement in a field of practice provides the organism with an "education of attention" ${ }^{\prime \prime}$. If attention is essential to accomplish a task, it is not possible to become a skilled practitioner just by observing. The subject must engage actively and experience acting in an environment made by his masters, "gets the 'feel' of things for himself" (Ingold 2000, p. 353)-we need to remember that in Dewey (2004) acquiring is preceded by the act of inquiring. In short, the proposition disassembles traditional models that consider that learning begins with the transmission and formation of mental representations, which are then applied and converted into action by the learner (see Ingold 2000).

If we do not put the practice itself between brackets, we understand that what we qualify as instruments "are not so much used as brought into use, through their incor-

6 This is a notion that Ingold (2001) borrows from the experimental psychologist James Gibson. 
poration into an accustomed (that is usual) pattern of dexterous activity" (Ingold 2000, p. 352). Skills, "then, are not preexisting properties of the user and the used, but rather immanent in the activity itself, in the gestural synergy of human being, tool and raw material". The agent's action, by perfecting and expanding what Ingold (2001) calls "powers of perceptual discrimination", might be more fluent and responsive to the propositions of the environment-or, in a word, skillful.

For Ingold (2001), instead of conceiving the skill separately, as something that precedes an activity, it would rather be the condition of the latter. In addition, it takes part in the growth not of a preformed body, but in a body whose forms emerge through abilities. Only in this sense, according to Ingold (2011), is it possible to address a skill as an acquisition. That is to say, when we can appreciate it in several moments of the life-cycle, keeping us within a history of development that translates into the skill less as an addition to a body and more as a formative vector. Curiously, on one occasion during the research, a flexible gay youth pointed to another as an example of someone whose contortionist skill was well-known due to his physical structure. Without even needing to dance, it was possible to identify that he "had a spine", due to the accentuated internal curve of the lumbar region. In this manner, a pattern of movement seems to imply a certain condensation or crystallization demonstrative of a particular use of the body ${ }^{7}$.

Basically, handrail can only be "loved" because it is part of a landscape pregnant with the past, so it relates to the practice of flexibility and to that which was made before. "Loving handrail" is not, therefore, the first act. My interlocutor can "love" it because specific things are already present in the environment for the practice of flexibility, which one learns to manipulate through active exploration. In addition, since organism and environment are complementary terms, which "each implies the other" (Ingold 1993, p. 156), speaking of the process of formation of a flexible gay man is often also to talk about handrail, walls, things, and environments. All these materials have "inherent properties that can be either expressed or suppressed in use" (Ingold 2007, p. 13). They are, therefore, also relational properties.

On the one hand, these objects aid the process of acquiring this body, on the other, during the process and when the body becomes flexible, such objects are no longer silent or indifferent (as a streetlight might be viewed by an ordinary person). Following once again in the steps of Latour (2004), one finds these objects under a new register, so that, able to be touched by them, now sensitive to their suggestions, it is possible to respond effectively to some of the questions of a richer and differentiated world. Hence, one acquires a body and inhabits a different world. Because the properties of objects and environments are related, they are not simply physical, but simultaneously a fact of the environment and a psychological fact, of the observer (Gibson 1986). Perceiving what the objects offer, their properties, is to perceive what they are. To perceive the potential that an object offers to a practice it is necessary however, to be "equipped".

In Latour (2004), the key to understanding the body would be neither "inside", in the body, nor "outside", in the world, but in this articulation and interaction. If one of the terms of the relationship is modified, so is the other. Finally, following Ingold's argument (Ingold 2001), if an organism can be defined as a center of attention and agency, building a flexible body also implies, as in Latour's perspective, the creation of a different environment. A stimulating environment in which one acts and experiences in a different way. An environment that is, at last, capable of serving as a cradle for the practice of flexibility. In these terms, skill in flexibility can be read as the skill to be attentive and responsive, to articulate and to involve oneself differently in a world.

It is our predecessors, according to Ingold (2001), who prepare the environment and make us sensitive to it. In the practice of flexibility, the mentors also taught that the

7 In this sense, Downey (2010) reconsiders an interesting discussion regarding how life styles and activities in which we are engaged are able to modify our physiology. As he convincingly argues, although it presents itself more obviously in athletes, we are all subject to this process of real bone remodeling. 
connection with environmental materials, necessary for the formation of a flexible body, is a tactile experience of pain. It is not just a question of being situated in the world. It is more than this. It is to open oneself to the world.

\section{The Relationship with Pain}

In the workshop for building the body of a flexible gay man, one does not only learn to experiment with materials and objects. In addition to using such materials, stretching exercises will also cause pain. As George claims, if you do not feel pain, it means the training is not working; it is not fulfilling its purpose. Therefore, if physical suffering could seem detrimental, in the context of the stretching exercises, it becomes promising, a good omen. Pain is understood as a sign of following the correct method so as to achieve the desired flexible body, which is how they learn to establish a new and distinct relationship with pain.

George's tale of resilience in the face of discomfort-as we already saw, the first time he stretched his legs on the wall, he wet himself-gave encouragement to the other gay men he was stretching, a group that at the time complained about the pain the exercises caused. Without the willingness to face the pain, for example, it is not possible to "fully open the legs on the wall", an image that can sound radical or extreme. To accomplish the act, one leans the legs against the wall as much as possible in a horizontal extension formed by the lower limbs (leg extensions). For that the novice usually needs the help of someone who, as George shows us, rarely in a delicate way, forces his body against the wall.

There are many ways to "stretch the leg on the wall". In one stretching session led by George, he guided two boys to push a young man's calves against the wall with their hands. Each one took care of one leg. "It's gonna wreck your shorts, bicha", someone said while watching the young man's side split getting closer ("to glue") to the wall-the purpose of the exercise. Like the split in general, where the aim is to "glue" the legs with the ground (making the full split ${ }^{8}$ ), perfectly aligned across the surface, the side split in the stretching exercises could also "glue" itself to a wall.

Those who wish to "open their side split", as they say, are recommended to do other exercises as well-one of which is the "butterfly". The pose, whose name I believe comes from the placement and movement of the legs suggestive of a flapping wing, is executed as follows: one sits as if in a lotus posture, but without crossing the legs; the soles of the feet must touch each other, while all the extension of the leg needs, at first, to be close to the ground. This way, one moves thighs, knees, and calves up and down in a continuous and fast-paced rhythm, while keeping the soles of the feet together and on the ground, with the help of the hands.

The major difficulty our dancers face is the "spread" of the initial position of the butterfly starting from the extension of the legs fixed on the ground. The help of a friend is welcome to meet this challenge. George guides one of them to stand on the other's body, placing his feet close to the knee of the one who is stretching. The person standing uses the weight of their body against the legs of the person who is stretching. In this manner, the legs spread themselves over the ground, reaching the desired extensions.

Commonly, this arrangement of bodies causes pain to those aspiring to flexibility. In one session between stretching exercises, we witness Nicolas' face tighten. His eyes now small, he fills his mouth with air, and, with his prominent cheeks, his mouth moves like he is blowing up a balloon. His expression seems to testify to someone seeking to overcome suffering. He looks at me as if trying to be understood in his pain, and touches his groin and complains: "This part here man, damn, it's hurting pretty bad". George, however, is unrelenting, and reminding him of the exercises Nicolas claims to have been practicing at home, answers the lamentation with irony, challenging him: "Hey, aren't you the one who stretches yourself?".

The full split can be defined when the legs form a horizontal line. 


\subsection{Sonorous Movements}

Nicolas finishes the stretching sequence and says: "Viado, I think I'll end up going around in a wheelchair, fuck me?!". However, while in the butterfly pose, George keeps playing hard, urging Nicolas to put more energy into throwing his legs against the floor: "Go, hit! I want some noise, Nicolas!". Everybody is attentive. The impact of his thigh hitting the floor produces a particular noise. The sound is the basis of an energetic butterfly experience, a bodily sound that tells of movement, the body's dynamics and its state. There is interchangeability between visual and auditory perception; one experiences it with the ears as much as with the eyes (Ingold 2000).

The master draws attention to the noise because, as in Wacquant's investigation (Wacquant 2004) in a boxing gym in Chicago, it indicates the correction of a gesture, of a blow. These onomatopoeias emerge in the descriptions of my interlocutors, as in Wacquant's descriptions, orienting the listener's or the reader's attention toward the rhythm and extreme movements that give life to the narrative-and the bodily practice. The boxing experience, beyond the noise provoked by panting, always seems to be made of noises, including the ones made by the materials that mediate the fight (for example, the glove). In that context, the noise seems more richly differentiated than among flexible gay men, as we can see in Wacquant's fieldnotes: "you know right away if you're hitting the bull's-eye because the pad makes a snapping sound instead of a muffled one" (Wacquant 2004, p. 64).

In the practice of flexibility, the gestures do not always produce noise. It depends on the surface that the body is throwns onto and collides with, as well as on the type of movement being performed. The impact will probably cause an imperceptible sound if a gay man jumps and falls into the splits on a beach or on the grass, no matter how high he throws himself. We will hear interjections of perplexity and celebration enunciated by the spectators. A split jump ${ }^{9}$ on the theater's wooden stage, however, invariably provokes noise-which is, by the way, very exciting. Depending on the ground's material, the sound expresses a movement that is rooted in space in relation to how it is experienced and lived through flexibility, and indicates an event's sensory placement (Bäckström 2014).

As I said, the distinct sounds produced in the boxing gym can attest to the correction of a blow, turning hearing into an important guide in the learning process ${ }^{10}$-as it was for Wacquant (2004), who was initiated into this art. In the practice of flexibility, the differences, occur in a single term: gradations of the same type of sound. With flexibility, these variations in sound seem to mainly indicate intensity, when the sound emitted becomes louder not only because of how high the split jump is, for example, or what the material of the surface against which the body collides is, but also due to the weight of the flexible gay man.

It is the intensity, physical vigor, and affecting quality (see the collisions) of many of the movements in flexibility, and the intensity which I have already observed in the situations of heated competition between our dancers, which leads to this plurality of onomatopoeias deployed by my interlocutors in their narratives, even when the gestures, such as the spread legs, cannot make noise. Such attacks illustrate the daring of the practice and its extreme nature from accounts that do more than reproduce events. Their accounts rework the past and retrace the path of movements, stressing, through the use of onomatopoeia, the distinctive characteristics of the physicality of a flexible gay man.

\subsection{The Pain of Action}

"I'll be honest with you ... It hurts", George admitted to me at a birthday party. "What hurts?", I asked him. "The ... flexibility, it hurts". Despite flexibility being a physically demanding practice, the facial expressions of those who perform it, in its public

9 As described in the section "The Scene" of this text, the split jump position is characterized by a leap combined with the legs between a full stretch to at least a $90^{\circ}$ angle.

10 It is also worth drawing attention to the insightful investigation of Fors et al. (2013), who consider sound as an analytic category, relevant for an understanding of how the learning of physical activity of skateboarding is situated through the senses. 
exhibition, are not usually of pain, but rather of courage or indifference. The expression of courage is possibly related to the efforts and even sacrifices that are involved in the corporal performance. However, it is also undoubtedly associated with tensions that are inherent to the practice of flexibility.

George's confession belies the impression that performing a sequence of energetic movements, sometimes accompanied by a blase facial expression-which brings an even greater appearance of effortlessness to the spectacle-can be painless. The stretching sessions seem elementary to get the flexible gay man used to the experience of pain, to such an extent that this is, in their public performance, expressively controlled.

In the field, I met gays who refused to be initiated into flexibility because of their fear of pain. In addition, at distinct moments, also because of physical suffering, flexible gay men thought about giving up the practice. Or they complained about pain in a trivial tone: "I've never been as injured as I am today". Beginning and giving up seem to be the right terms to refer to a relationship or commitment that requires cultivation, work, and patience, as we will see below.

In the stretching sessions, one learns to face pain not as an obstacle but as a necessary step in the growth of a flexible body. As such, the practitioners should be drawn toward the pain. "Does it hurt?", George asks a flexible gay man as he stretches. He replies: "not yet", and George rushes to say: "Make it hurt". Besides George, six flexible gay men were making a circle. They are sitting on the floor with their legs stretched out and each foot touching the other's, then George asks them to hold hands. The colleague on the left and the colleague on the right must simultaneously pull their clasped together hands. This arrangement puts pressure on the leg extensions. George continues the orientation: "Go! Pull until he complains! Pull until he wants to quit!".

In this relationship with pain, there are some points to consider. The first is that the exercise whose intensity causes pain should not be immediately interrupted to get rid of the penury they feel. That is one sense of the virtue of patience. One must tolerate and bear the pain. Therefore, one must live with it; to exist with, amid, and not to remove pain immediately. For this, there are some tricks: "to count to ten", "to hold on until it stops hurting", "take a deep breath, which relieves the pain".

The second is that there is a sense of an optimal level of pain, which may be difficult for a non-practitioner to understand. Exercising far below this level is useless, while over-exerting oneself can be dangerous, causing the so-called "strain". The strain is a pain modality among flexible gay men-I would say the most commonly named-and can force the dancer to take some days to recover, without being able to exercise. It was to avoid this outcome that George warned on the occasion of the stretching circle: "stay calm, don't go crazy! Each one pulls only as far as possible".

On another occasion, George warned: "It'll cause you a strain if you put too much force into it". That is the other sense of patience that should orient stretching. To become capable of certain movements whose performance is quite forceful, it is important to respect the generation and regeneration of the body. In other words, its growth. Thus, George, trusting in the silent work of time, does not recommend repeating some exercises every day to give the body time to recover. The care of a flexible body involves an alternation between intense effort and resting.

If sleeping is essential for a teenager's growth spurt, resting is essential to a flexible body's growth, to which stretching is dedicated. It does not oppose this process; it collaborates with one's growth. In this sense, the reverse of growth is not resting, which composes its own rhythm, it is to overcome yourself. The excess that causes a strain leads to an enforced stillness, making it impossible, sometimes for days, to continue. The ability to continue growing is contingent on adequate rest.

That is the third prominent aspect of the association between stretching and pain. We already know that one pursues pain when stretching, a goal that is expressed by George's "until" ("pull until he complains!"), or by a dancer from Aalten's research (Aalten 2005, pp. 59-60): "[I] pushed my legs wider until they hurt. The next day I could go a bit further". 
If the pain, defined in the dancer's experience as a "sign of improvement" (ibid., p. 60), presents a limit, the "until" we reach our limit, it is a provisional limit. That is because pain, as a goal to be reached in the stretching exercises, does not represent the end, but the development itself, so that pushing the body to a limit is already expanding this limit.

Thus, the stretching, which calls for pain, prepares new extensions and capabilities, and new limits, which later will be undone while new ones blossom. Stretching oneself is to negotiate actively with possibilities, to explore capacities, to experiment and know resistances, to test limits, to incorporate surpluses, to achieve minor victories over oneself. The stretching enters unequivocally into dialogues with the primacy of movement in Tim Ingold's conception of life, modulated by rhythm and patience, rest and recovery, gradations, and advances. For the author, "the path, not the place, is the primary condition of being" (Ingold 2008, p. 1808). As we have seen, in the stretching, every place achieved by the body "is already on the way to somewhere else" (Ingold 2015, p. 135).

Both the "go a bit further" than Aalten's dancer and the "evolution" of flexible gay men, a verb so often used as the ultimate goal of the stretching sessions, signals the idea of a path, career and movement, as well as a sense of overcoming and growth. Ingold (2015) finds in the sense of growth a basis that unites not only humans but also nonhuman animals, plants, and things. For him, the limits of these heterogeneous entities would be dismissed in favor of a broader movement of growth and of formation, which crosses the environment itself.

The environment, instead of being characterized as the surroundings of the organism, would be the zone of entanglement (Ingold 2008) in which the entities grow while equally expanding the environments range. We can say that growth is a property of these entities, but also of the environments, with the growth of both elements of the relation contributing and playing a role in the other's formation as entangled entities. Thus, each entity develops amid admixture of trails of growth, each one being a bundle of interconnections.

That is basically what we discussed in this essay about becoming a flexible gay man. They grow themselves and "since their growth is conditioned by the presence and actions of others, they grow one another" (Ingold 2015, p. 120). "Growing one another", an expression considered by Ingold (2015) to be a good definition for social life, is an accurate description also for the stretching sessions I accompanied. These sessions take place in a force and relationship field in which other flexible gay men take part-experts and beginners-in sounds, architectural elements, and objects. Through the movement (and rest) that produces growth, new forms emerge, are generated and regenerated. Shapes like the spine, if not gradually decomposed, are challenged, while another spine can be created.

Finally, I could not avoid a last observation regarding this topic. The consideration, which relates to sensitive experience and form, indicates another reason flexible gay men seek to stretch themselves. Even those who are already flexible. Let us take side split as an example. Those who already "have side split" can stretch to "glue it" (on the floor) and "complete its", as they also say, or further still, to make it "dead".

"Dead" is how they refer to movements whose performance no longer causes pain. If the exercises aim at "evolution" and growth, it is as if, after a stubborn series of stretches, the side split one no longer has the means to grow. Once they have achieved a form that would be complete, it would be dead. Maybe that is why gay men who are "truly" flexible, the most proficient, insist on saying that they do not need to stretch themselves.

My interlocutors may agree with Ingold (2015), for whom life comprises a continuous process of growth-"not just in strength and stature" (p. 125), but also in skill and knowledge, since they attribute this adjective to some gestural forms, an adjective whose use seems to bind growth to pain. In addition, with the painter Paul Klee, who, as Ingold (2010) shows us, understands the way of death. More than genesis and gestation of forms; however, living understands the decomposition and maintenance of forms. As one gay man told me on one occasion, in his words, he retired from dancing: "you're good when you're stretching, but after you stop stretching, you lose everything". 


\section{Conclusions}

Gay youths from poor neighborhoods in diverse regions of Brazil display techniques of bodily flexibility in their dancing. Such performances have already appeared on national television programs. Additionally, recent musical production by LGBTQ artists (originating, for example, in the Brazilian Amazon region)-the lyrics of which encourage the public to perform diverse movements that I attempted to describe here-, reflect the codification of these gestures and the spread of this style nationally. Even with this being case however, I am unable to say to what extent the findings of the present ethnography, conducted with a group of gay teenagers from the city of Salvador de Bahia (Northeastern Brazil), would be applicable for other gay practitioners of flexibility.

I investigated here some ways of becoming a flexible gay man. Although there is no single script for this undertaking, stretching is an unavoidable activity in the formation of this body I considered gay men who wish, with their muscles, nerves, and tendons, to be a part of the "dance world" with the potential extravagance offered by this gymnastic repertoire.

I sought to think of stretching as a way to make a body grow. It is the tenacious engagement in the active leisure that enables the growth of these bodies. As we have seen throughout this essay, caring for the growth of a flexible body involves the collaborative participation of others. These others could be human-as when more experienced flexible gay men show a willingness to teach their young friends-or nonhuman-as with certain objects and architectural elements, which one learns to manipulate in diverse ways, learn to compose specific arrangements and connections through the use of their forms.

Therefore, the body of a flexible gay man is, primarily, an entangled body, and a body that has learned to entangle itself through the development of a set of sensibilities. To be present in the world in this way is also to inhabit a different world, given that bodies, things, and environments do not detach from their uses, practices, or relationships. Therefore, the body that opens itself through stretching also opens a world richer in possibilities; they are co-constitutive elements. Spatialized learning, which is a part of flexibility, and a dimension highlighted as we say by the noise of the movements, also invites us to consider flexibility not as well-bounded but a distributed phenomenon. The lexicon circulating between my interlocutors also highlights this primordial link with practice, with the situated experience of a body (in a field) in motion.

It is from this perspective I argue that "having a spine", the paradigmatic idea for flexible gay men should be approached. Flexible gay men report to the body through skillful practice. The empirical examples considered here provide help to investigate more thoroughly how the "having" consists at the same time in the obtainment of kinesthetic resource would be immanent and emergent inthe growth of motor faculties rather than an a priori condition. It is likely that the gestural transformation that happens within the body has consequences for its form, such that while bodies make gestures, postures also make bodies (Ingold 2011).

The "to have" testifies to the aspect of embodiment. However, it also reveals the character of a bond which as such, demands care, cultivation, and commitment. Forms are created and sustained, challenged, decomposed, and transformed and regenerated. In the physical culture of flexibility, pain is part of this process of immanent bodily plasticity. As a sign orienting the path that produces this acrobatic body, it must be invited. At the same time, however, while the necessary care required to make a flexible body grow includes learning to provoke pain, a wise dancer must also encounter a balance with adequate rest. The challenge remains to encounter a judicious balance in this intense and vibrant bodily life.

Funding: This research received no external funding.

Institutional Review Board Statement: This study followed the normative guidelines of Resolution $510 / 2016$ of the Brazilian National Health Council, which determine the treatment for human beings as concerns conditions specific to domains of Social Sciences and the Humanities. In accordance 
with this norm, the present study did not have to be submitted to the Research Ethics Committee. Its ethical evaluation and ethics administration review procedures, both at the early stage of the conception of the research project, and during the ongoing fieldwork, was the responsibility of the research supervisor, likely to be appropriate also in terms of departmental and faculty policies. The research was discussed and monitored by the individual supervisor including through the sending of partial reports during the fieldwork. Finally, the precise requirements prescribed by the University's policies and procedures governing established research ethics and the Resolution 510/2016 aim at protecting the human rights of participants in studies, in line with universal values that guide standard ethical practices, such as the recognition of the autonomy of the research participants, justice, a beneficence and non-maleficence. The realization of the research in accordance with the necessary ethical guidelines reflected, therefore, professional as well as community standards.

Informed Consent Statement: In accordance with the Resolution 510/2016 of the Brazilian National Health Council, before collecting the data, each subject provided verbal consent and, when applicable, verbal assent was obtained from parents for their sons to take part in the study.

Data Availability Statement: The data presented in this study are available upon reasonable request from the corresponding author. The data are not publicly available due to privacy or ethical restrictions.

Conflicts of Interest: The author declares no conflict of interest.

\section{References}

Aalten, Anna. 2004. 'The Moment When it All Comes Together': Embodied Experiences in Ballet. European Journal of Women's Studies 11: 263-76. [CrossRef]

Aalten, Anna. 2005. In the Presence of the Body: Theorizing Training, Injuries and Pain in Ballet. Dance Research Journal 37: 55-72. [CrossRef]

Asad, Talal. 2002. Remarks on the anthropology of the body. In Religion and the Body: Comparative Perspectives on Devotional Practices. Edited by Sarah Coakley. Cambridge: Cambridge University Press, pp. 42-52.

Aull Davies, Charlotte. 1999. Reflexive Ethnography: A Guide to Researching Selves and Others. London and New York: Routledge.

Bäckström, Åsa. 2014. Knowing and teaching kinaesthetic experience in skateboarding: An example of sensory emplacement. Sport, Education and Society 19: 752-72. [CrossRef]

Bäckström, Åsa, and Anne-Lene Sand. 2019. Imagining and Making Material Encounters: Skateboarding, Emplacement, and Spatial Desire. Journal of Sport and Social Issues 49: 1-21. [CrossRef]

Bilate, Lucas Ferreira. 2017. Brilho em Festa: Homossexualidades Masculinas em Escolas de Samba. Ph.D. dissertation, Universidade Federal do Rio de Janeiro, Rio de Janeiro, Brazil.

Birman, Patricia. 1995. Fazer Estilo Criando Gêneros: Possessão e Diferenças de Gênero em Terreiros de Umbanda e Candomblé no Rio de Janeiro. Rio de Janeiro: Relume Dumará, EdUERJ.

Cambria, Vincenzo. 2014. Samba de Roda. In Bloomsbury Encyclopedia of Popular Music of the World, vol. 9, Genres: Caribbean and Latin America. Edited by David Horn, Heidi Feldman, Mona-Lynn Courteau, Pamela Narbona Jerez and Hettie Malcomson. London and New York: Bloomsburry, pp. 752-54.

Collier, John, Jr., and Malcom Collier. 1986. Visual Anthropology: Photography as a Research Method. Albuquerque: New Mexico University Press.

Dewey, John. 2004. Democracy and Education: An Introduction to the Philosophy of Education. Delhi: Aakar Books.

Dicks, Bella, Bambo Soyinka, and Amanda Coffey. 2006. Multimodal Ethnography. Qualitative Research 6: 77-96. [CrossRef]

Downey, Greg. 2010. Throwing Like a Brazilian: On Ineptness and a Skill-shaped Body. In Anthropology of Sport and Human Movement: A Biocultural Perspective. Edited by Robert R. Sands and Linda R. Sands. Lanham and Plymouth: Lexington Books, pp. 297-326.

Fors, Vaike, Åsa Bäckström, and Sarah Pink. 2013. Multisensory Emplaced Learning: Resituating Situated Learning in a Moving World. Mind, Culture, and Activity 20: 170-83. [CrossRef]

Fry, Peter. 1986. Male Homosexuality and Spirit Possession in Brazil. Journal of Homosexuality 11: 137-53. [CrossRef] [PubMed]

Gibson, James J. 1986. The Ecological Approach of Visual Perception. Hillsdale: Lawrence Erlbaum Associates.

Hökelmann, Anita, Gaia Liviott, and Tina Breitkreutz. 2013. Rhythmic Gymnastics. In Routledge Handbook of Sports Performance Analysis. Edited by Tim McGarry, Peter O'Donoghue and Jaime Sampaio. London and New York: Routledge, pp. 475-83.

Ingold, Tim. 1993. The Temporality of the Landscape. World Archeology 25: 152-74. [CrossRef]

Ingold, Tim. 2000. The Perception of the Environment: Essays on Livelihood, Dwelling and Skill. London: Routledge.

Ingold, Tim. 2001. From the Transmission of Representations to the Education of Attention. In The Debated Mind: Evolutionary Psychology versus Ethnography. Edited by Harvey Whitehouse. Oxford: Berg, pp. 113-53.

Ingold, Tim. 2007. Materials against materiality. Archaelogical Dialogues 14: 1-16. [CrossRef]

Ingold, Tim. 2008. Bindings against Boundaries: Entanglements of Life in an Open World. Environment and Planning A: Economy and Space 40: 1796-810. [CrossRef] 
Ingold, Tim. 2010. Bringing Things Back to Life: Creative Entanglements in a World of Materials. NCRM Working Paper Series 5: 1-14. Ingold, Tim. 2011. Being Alive: Essays on Movement, Knowledge, and Description. London: Routledge.

Ingold, Tim. 2015. The Life of Lines. London and New York: Routledge.

Ingold, Tim, and Jo Lee Vergunst. 2008. Introduction. In Ways of Walking: Ethnography and Practice on Foot. Edited by Tim Ingold and Jo Lee Vergunst. Aldershot: Ashgate, pp. 1-19.

Landes, Ruth. 1940. A Cult Matriarchate and Male Homosexuality. Journal of Abnormal and Social Psychology 35: 386-97. [CrossRef]

Larsson, Håkan. 2020. Learning Movements: New Perspectives of Movement Education. New York: Routledge.

Latour, Bruno. 2004. How to talk about the body? The normative dimension of science studies. Body E Society 10: 205-29.

Lave, Jean. 1993. The practice of learning. In Understanding Practice: Perspectives on Activity and Context. Edited by Seth Chaiklin and Jean Lave. Cambridge: Cambridge University Press, pp. 3-32.

Leacock, Seth, and Ruth Leacock. 1972. Spirits of the deep: A study of an Afro-Brazilian cult. New York: Doubleday Natural History Press.

Mauss, Marcel. 2007. Techniques of the Body. In Beyond the Body Proper: Reading the Anthropology of Material Life. Edited by Margaret M. Lock and Judith Farquhar. London: Duke University Press, pp. 50-68.

Merleau-Ponty, Maurice. 2008. The World of Perception. New York: Routledge.

Merleau-Ponty, Maurice. 2014. Phenomenology of Perception. Milton Park: Routledge.

Mizrahi, Mylene. 2019. Figurino Funk: Roupa, Corpo e Dança em um Baile Carioca. Rio de Janeiro: 7 Letras.

Mol, Annemarie. 2002. The Body Multiple: Ontology in Medical Practice. Durham and London: Duke University Press.

Nash, Roy. 1999. Bourdieu, 'Habitus', and Educational Research: Is It All Worth the Candle? British Journal of Sociology of Education 20: 175-87. [CrossRef]

Noleto, Rafael. 2016. Brilham Estrelas de São João: Gênero, Raça, e Sexualidade em Performance Nas Festas Juninas de Belém-PA. Ph.D. dissertation, Universidade de São Paulo, São Paulo, Brazil.

Palombini, Carlos. 2013. Funk Carioca and Música Soul. In Bloomsbury Encyclopedia of Popular Music of the World, vol. 9, Genres: Caribbean and Latin America. Edited by David Horn, Heidi Feldman, Mona-Lynn Courteau, Pamela Narbona Jerez and Hettie Malcomson. London and New York: Bloomsburry, pp. 317-25.

Pereira, Pedro Paulo Gomes. 2019. Queer in the Tropics: Gender and Sexuality in the Global South. Cham: Springer.

Silva, Vinicius Santos da. 2019. Notas Etnográficas sobre Homens Negros Balizadores de Fanfarra em Salvador. Cadernos de Gênero e Diversidade 5: 192-215.

Sneed, Paul. 2008. The "Bailes Funk" in Rio's Crisis of Social Exclusion and Violence. Latin American Research Review 43: 57-79. [CrossRef]

Toth, Lucille. 2017. Praising twerk: Why aren't we all shacking out butt? French Cultural Studies 28: 291-302. [CrossRef]

Wacquant, Löic. 2004. Body E Soul: Notebooks of an Apprentice Boxer. New York: Oxford University Press.

Wafer, Jim. 1991. The Taste of Blood: Spirit Possession in Brazilian Candomble. Philadelphia: University of Pennsylvania. 